\title{
EXPLORING THE POTENTIAL OF NIGHTSCAPE PHOTOGRAPHY FOR TOURISM: PRELIMINARY INSIGHTS
}

\author{
ÁUREA RODRIGUES, ${ }^{*} \dagger$ ROSÁRIA PEREIRA, $+\$$ AND ANA ISABEL RODRIGUES『 \\ *CIDEHUS, School of Social Sciences, Department of Sociology, University of Évora, Évora, Portugal \\ $\uparrow$ GOVCOPP-University of Aveiro, Aveiro, Portugal \\ \$School of Management, Hospitality and Tourism, University of Algarve, Faro, Portugal \\ $\S$ CinTurs -The Research Centre for Tourism, Sustainability and Well-Being, \\ University of Algarve, Faro, Portugal \\ ףHigher School of Technology and Management, Management Department, \\ Polytechnic Institute of Beja, Beja, Portugal
}

\begin{abstract}
The analysis of photo imagery has all been done based on daytime images, not photographs taken by night. In this sense, it is relevant to study tourists' perceptions of dark night pictures to understand how they can be used by DMOs and advertising agencies to promote the nightscape of a destination. Therefore, the purpose of this article is to explore the perceptions and the emotions evoked by the nightscape pictures based on the principles of environmental psychology, compared to daytime landscape preferences. It also aims to understand if the elements presented in daytime pictures, which turn a certain landscape appreciated, apply to nightscape pictures and, consequently, how they can be used in tourism promotion and branding. An exploratory study was carried out based on the photoelicitation method, demonstrating the benefits of the combined use of textual and pictorial data. Results show that elements that are key during the day are not the same at night, such as complexity and points of reference. On the contrary, the preferred nightscape is based on simple open spaces, where the human eye could prospect security.
\end{abstract}

Key words: Astrotourism; Nightscape; Landscape preferences; Destination image; Photo-elicitation

Introduction

Nowadays tourists do not just seek rural life activities in rural destinations, they search for all the activities that are possible to do in destinations with nature assets. Furthermore, in the last few years, many rural destinations emerged in Europe, leading to increasing competition, which resulted in those places developing niche products to attract different markets and create a different image

Address correspondence to Áurea Rodrigues, CIDEHUS, School of Social Sciences, Department of Sociology, University of Évora, Évora, Portugal. E-mail: aor@uevora.pt 
from the competitors. One of those activities that has been emerging and growing is astrotourism or celestial ecotourism (Weaver, 2011). The latter can be defined as:

\begin{abstract}
an activity of travelers wishing to use the natural resource of well-kept nightscapes, for astronomy related leisure and knowledge. This practice has increased in popularity during the past few years, adding value to offbeat tourism destinations offering high quality night skies and astronomical or archaeoastronomical heritage. (Fayos-Solà, Marín, \& Jafari, 2014, p. 663)
\end{abstract}

The promotion of a destination is done in most cases through images (Pritchard \& Morgan, 2003) in tourism brochures, sites, and other media resources, and in this tourism niche nighttime pictures are used in opposition to the traditional daylight photographs. In the case of destinations specialized in astrotourism the use of nightscape photographs is expected, independently of the emotions that they evoke. Given the tendency for destinations to begin diversifying their offerings into nighttime tourist activities, the presentation of night landscape photographs requires some prudence, given the paucity of studies on the effects and emotions they evoke in tourists.

According to Albers and James (1988), "photographs are vital to successfully creating and communicating images of a destination. They have been used to gain understanding of the tourist (through photographs taken) and the process by which tourist destinations are represented" (p. 134). The analysis of photo imagery has all been done based on daytime images, not photographs taken by night, but because photography forms a space of mediation to create a sense of place and captivates the interest of the consumer (Kim \& Stepchenkova, 2015; Lester \& Scarles, 2013) it is relevant to study the perceptions of tourists of night pictures to understand how they can be used by DMOs and advertising agencies to promote the nightscape of a destination. Therefore, the purpose of this exploratory study is to analyze the perceptions and the emotions evoked by the nightscape pictures based on the principles of environmental psychology, compared to the daytime landscape preferences already studied. It also aims to understand if the elements presented in daytime pictures, which show a certain landscape favorably, apply to nightscape and, consequently, how they can be used in tourism promotion and branding.

The Relevance of the Pictorial Element in Tourism Destination Image

The present study is also anchored on destination image (DI) theory produced since the early 1970s. Hunt's (1975) prominent work was decisive for the materialization of DI studies when he stated that, "it is possible that images, as perceived by individuals in the travel market, may have as much to do with an area's tourism development success as the more tangible recreation and tourism resources" (p. 1). Since that time, DI has been a vigorous research area, building theory and producing results. Terms such as "organized representations," "sum of beliefs, ideas," "complex combination," "overall impression or attitude," and "visual or mental impression" have been used to define it. More recently in the 2000 s, a still greater number of researchers agree that destination image is an "overall impression" or a "combination" (for more information see Rodrigues, Correia, \& Kozak, 2012). As Pearce (1988) pointed out, "image is one of those terms that will not go away, a term with vague and shifting meanings" (p. 162).

Due to the complexity in measuring DI construct mentioned by several authors (Baloglu \& McCleary, 1999; Echtner \& Ritchie, 1993; Gallarza, Saura, \& Garcia, 2002), alternative methods of DI assessment based on qualitative techniques started to be proposed. By the mid-1990s, some researchers started to be skeptical about the validity of attribute lists, demonstrating the benefits of using a qualitative approach. Reilly (1990) introduced a free elicitation technique as an alternative approach and successive works follow this line (e.g., Coshall, 2000; Pike, 2007). Dann (1996) marked a turning point in the operationalization and measurement of the DI construct. A broad model for conducting DI research, which first incorporates a qualitative phase followed by quantitative methods, was proposed by Jenkins (1999). Her work makes it clear that the quality of DI research will improve from combining qualitative and quantitative methods.

Framed by this rational, the use of the visual element in destination image research is materialized 
in the so-called "visual movement" (Heisley, 2001). Researchers today have a set of data at their disposal with visual support such as paintings, photographs, postcards, promotional films, and drawings, among others, allowing the introduction of new interpretive elements that enrich the analysis and understanding of destination image as an object of study. Feighey (2003) vigorously highlighted the important potential contribution of visual-based research in tourism studies when he stated that, "the considerable theoretical and methodological space between researcher-found images and researcher-created images potentially offers tourism scholars opportunities to establish alternative approaches to vision and visuality in tourism" (p. 77). Jacobsen (2007) corroborates this idea by specifying the application of photo-based research approaches in tourism. In fact, visual stimuli such as travel photography have been used as a methodological approach (e.g., Pan, Lee, \& Tsai, 2014; Rodrigues, Correia, Kozak, \& Tuohino, 2015).

This stage marks the beginning of using photographs to extract information from people, particularly the use of photographs to provoke a response, which became known as the photo-elicitation technique (Harper, 1984, 2002). Photography and tourism are widely considered to be inherently linked (Garrod, 2009) and techniques such as reflexive photography and photo-elicitation started to be adopted in tourism research, specifically in destination image studies (see MacKay, 2005, for more detailed information).

\section{Methodology}

In this exploratory study, interviews based on photo-elicitation were used. The interviews aimed to analyze the nighttime picture preferences of a group of eight respondents between the age of 19 and 54 (none of whom had previously done any activity related to astrotourism or had any hobby related to astronomy or night photography). This methodology was also used by an international group of researchers to analyze aesthetics and astronomy by the Chandra X-ray Center, operated for NASA by the Smithsonian Astrophysical Observatory (Chandra.si.edu). The interviews had a duration of $2 \mathrm{hr}$. The pictures were presented for 5 min and each respondent had to answer a set of questions related to the theoretical principles used in the selection of the photographs.

According to Patton (2002), the interview method becomes a necessity when the researchers need to draw attention to that which they cannot observe, and when they want to capture participants' "feelings, thoughts, intentions," previous behaviors, or the ways in which people organize their mental understandings and then connect these understandings to their world (Richard \& Lahman, 2015). Regarding photo-elicitation, this started to be used as a method by the anthropologist Collier (1967), who studied the phenomenon of migration caused by economic and technological changes. $\mathrm{He}$ emphasized the fact that the use of photos evokes participants' memories, allowing for deeper and richer interviews. Sociologists Harper $(1997,2002)$ and Banks (2001) have contributed greatly to the recognition of photo-elicitation as a visual method, based on the simple idea of applying and conducting an interview using photographs as a stimulus.

Photo-elicitation is a research method whereby photographs chosen by the researcher or the respondent are presented in an interview situation (Pachmayer \& Andereck, 2017). The difference between interviews using images and text, and interviews using words alone lies in the ways the interviewee respond to these two forms of symbolic representation. For Harper (2002), this has a physical basis: the parts of the brain that processes visual information is evolutionarily older than the parts that process verbal information. Thus, images evoke deeper elements of human consciousness than words; exchanges based on words alone utilize less of the brain's capacity than exchanges in which the brain is processing images as well as words.

The photographs chosen for the photo-elicitation interviews were from Alqueva in the region of Alentejo and from the Azores, which are both destinations located in Portugal as well as from the Atacama Desert in Chile. All pictures were taken by the same professional astrophotographer. For the development of the questions, models widely used in the area of landscape studies, human ecology, and environmental psychology based on the principles of perceptionbased approach where the landscape is represented by photographs and in this case on semiovert questions were used (Milhaud, 2001). According to researchers (Downes \& Lang, 2015; Herzog, 1987), 

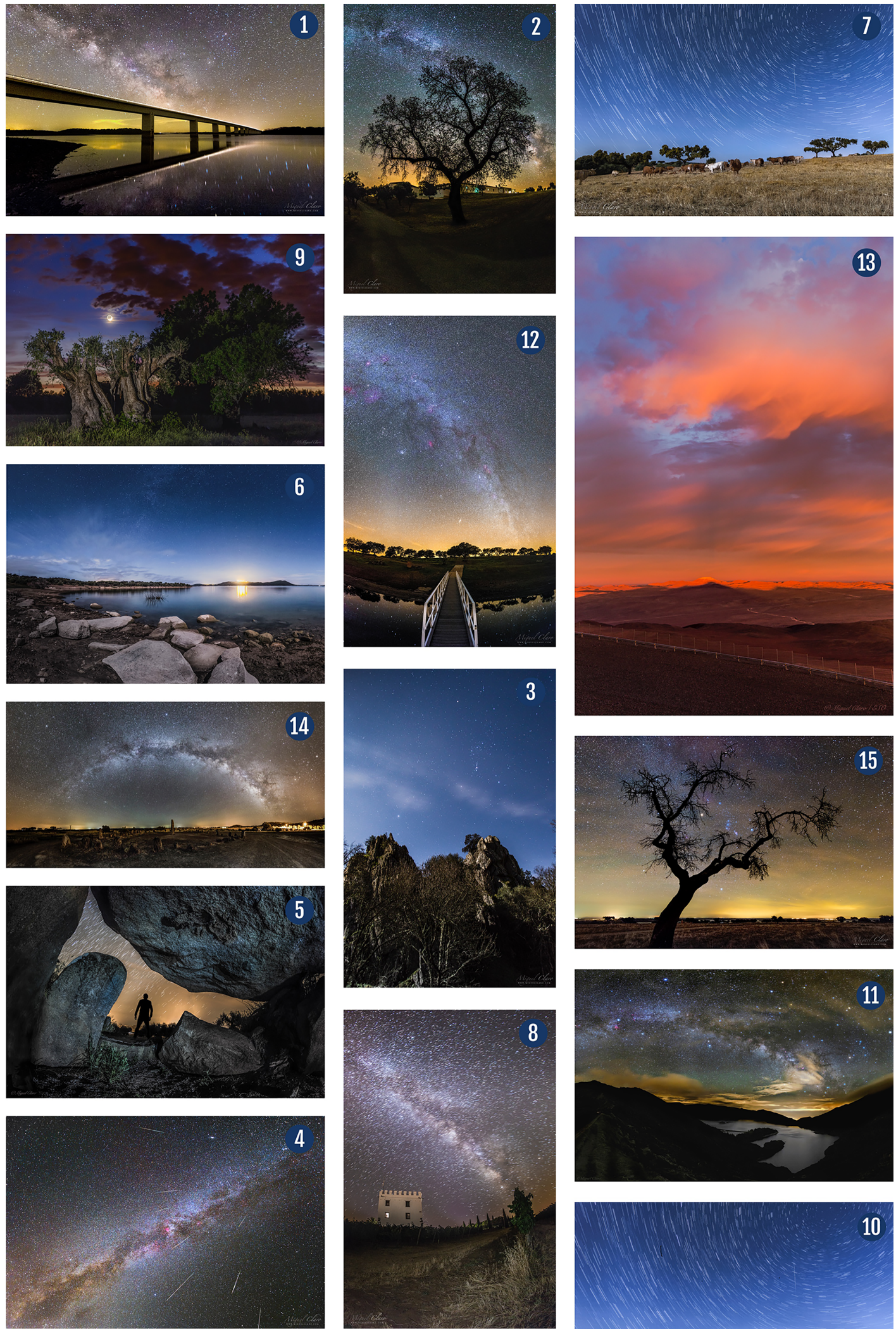

Figure 1. Photos used in the study. Source: Miguel Claro, astrophotographyC). 
the internal reliability of landscape preferences and/ or aesthetic assessment measurement based on small to moderate sized groups of observers/judges ( 5 to 30 ) has consistently been very high.

The pictures were chosen based on whether they had the elements that correspond to landscape, which according to Burton's (1999) principles, are as follows:

- Relief and geology: The relief determines the presence of many of the resources that can form the basis of some of the activities in nature (photos $1,6,11$, and 12).

- The natural vegetation and the animals that depend on it. The vegetation varies according to the climate of the region where it occurs (photo 2, $7,9,11,12$, and 15), introduced by man through agriculture and afforestation.

- The presence of man as a part of the natural vegetation has been altered (photos 1, 5, 8, 12, and 14).

The principles of Litton (1972) were also considered as a criterion to select the pictures, and relate to the organization of the components that constitute the landscape that determine the direction of our attention:

- Focus: the degree to which a scene provides its framing, allowing the viewer to quickly focus on key points (photos 1, 2, 5, 9, 12, and 15).

- Convergence: the point at which two or more lines of a scene meet and dominate it, drawing attention to a point on the horizon (photos 1, 2, 4, $8,11,12,14$, and 15).

- Contrast is associated with different shapes, textures and colors that appear in the landscape (photos 1, 4, 5, 6, 8, 10, 11, 13, and 14) (see Fig. 1).

Furthermore, this research is based on Russell and Lanius's principles (1984) to evaluate the emotional impact of a certain environment. According to Bakker, Vordt, and Vink (2014) this model is still useful to access and describe environmental experiences and has been used by researchers in environmental psychology and landscape preferences (see Fig. 2).

Lastly, this exploratory study includes the "system of preferences" model, developed by Kaplan and Kaplan (1989), which is a matrix that divides the environmental perception into four dimensions (see Fig. 3), two of which refer to the components that are being observed (coherence and complexity), and the other two reflecting sensations experienced in the future (readability and mystery).

Therefore, content analysis of text and pictures is the foundation for the present study based on the rational that there are advantages in using a more integrated approach in data analysis, by combining textual and visual elements (Rodrigues, 2018). The combination is used as a research technique for making replicable and valid inferences from data to their context (Krippendorff, 1980). In fact, Miles and Huberman (1994) argued, "Photographs, videotapes, or any other item that can be made into text are amenable to content analysis" (p. 240). The analytic procedure was based on the general stages of content analysis procedure in Krippendorff's (1980) six steps (design, unitizing, sampling, coding, drawing inferences, and validation). The goal here was to adopt a mixed interpretativequantitative approach of content analysis, in order to measure the information.

The qualitative step of these categorizations and analysis consists of a methodological controlled assignment of the category to a passage of text. A descriptive method that "summarizes in a word or short phrase - most often as a noun - the basic topic of a passage" (Saldaña, 2009, p. 70) was adopted.

\section{Results}

The analysis of the photographs was streamlined based on two phases. During the interview the predominant emotions identified by the respondents evoked by each of the photos were evaluated according to Russell and Lanius (1984). Departing from that analysis, the images were divided into three groups: negative emotions, positive emotions, and no predominant emotion. The photographs were then analyzed in accordance with the principles of the "system of preferences" (Kaplan \& Kaplan, 1989). In this study photos 1, 2, 7, 10, 11,12 , and 15 did not evoke any predominant emotion in the respondents. Viewing pictures is an aesthetic task, and according to some authors there appears to be a close association between attention and emotion, and affective intensity of a picture 


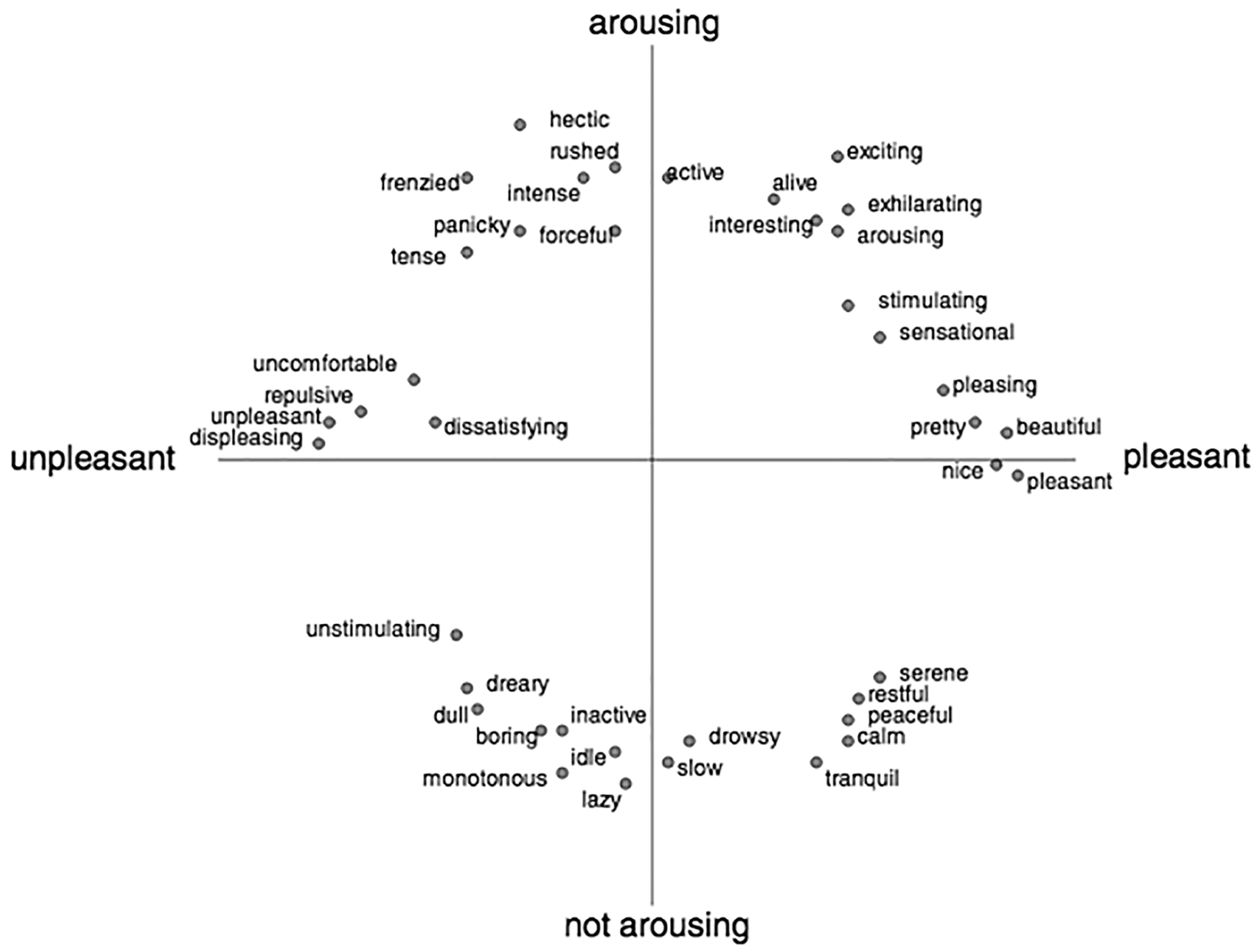

Figure 2. Model adapted from Russell and Lanius (1984) and Bakker et al. (2014).

\begin{tabular}{|c|c|c|}
\hline \multirow[b]{2}{*}{ Level of interpretation } & \multicolumn{2}{|c|}{ Informational needs } \\
\hline & Understanding & Exploration \\
\hline Immediate (2-dimensional) & $\begin{array}{l}\text { Coherence } \\
\text { Immediate understanding } \\
\text { of how elements in the } \\
\text { environment fit together }\end{array}$ & $\begin{array}{l}\text { Complexity } \\
\text { Visual richness that can be } \\
\text { immediately explored }\end{array}$ \\
\hline Inferred (3-dimensional) & $\begin{array}{l}\text { Legibility } \\
\text { Understanding of what } \\
\text { lies ahead and how you } \\
\text { could your way and not } \\
\text { to get lost }\end{array}$ & $\begin{array}{l}\text { Mystery } \\
\text { The promise of new things to } \\
\text { explore if moving further into } \\
\text { the landscape }\end{array}$ \\
\hline
\end{tabular}

Figure 3. The system of preferences. Adapted from Kaplan and Kaplan (1989) and Tveit, Sang, and Hagerhall (2012). 
percept determines its memorability (Balling \& Falk, 1982; Gobster, Nasauer, Daniel, \& Fry, 2007; Wang \& Sparks, 2016). Based on this perspective these pictures were not considered for the following analysis.

\section{Negative Emotions}

The photos that evoke negative emotions in respondents are $3,4,8$, and 13 . In photo 3 the prevailing negative emotion is "boring," and in photo 4 "rushed" (see Fig. 2). Although the photos are quite different, they have little complexity according to the respondents, who identified only five elements (sky, rocks, trees, stars, light) in the scene shown, and three elements (celestial elements, colors, lights) in photo 4 . For respondents, these photos show little diversity or richness of elements. However, these two photos are both coherent according to respondents, since they can identify the components in the photographs "It's coherent, without contradictions and leaves me no doubt" (photo 3) and "It's a logical image and it makes sense" (photo 4). In terms of the three-dimensional interpretation of the photos, photo 3 lacks legibility, once the majority of the respondents find no reference or landmarks, "I could easily get lost" (photo 3). Legibility in photo 4 is also a weak dimension as respondents can't find their way around it: "It lacks clear reference points" and "It does not seem that there is anything to explore beyond the observation of what is in the picture" (photo 4).

In both photos (3 and 4), mystery, which also corresponds to the three-dimensional interpretation of a scene, is revealed by the possibility of exploration, and leads the respondents to imagine something beyond the scene: "I imagine a river at the end of the road" and "possibility of exploitation" (photo 3); and "where can I see this? (wish to explore)" and "Because the man is waiting to hurt me" (photo 4).

In photo 8 the predominant emotion is "uncomfortable" and in photo 13 is "intense." Concerning complexity, photo 8 is considered moderate in its diversity of elements. Respondents identified "colors," "shadows," "light of the stars," and a "building" as main components. In photo 13 , only three elements are predominant - "the red tones of the sky," "the clouds," and "the road"- enhancing the poorness of the diversity dimension. The same happens concerning coherence; only three of the respondents agreed that the photo had some coherence: "Coherent, well-articulated organization of the space between the night landscape and the effects of the starry sky," "Yes, it's coherent, balanced elements." Most of the respondents thought it wasn't a logical environment as they do not understand what is going on: "It is not logical or coherent, light does not give me any guidance." Photo 13 gathered six positive responses concerning coherence; for example: "Yes, it's coherent, it has balanced elements" and "It seems to be organized representing the earth below and the sky above." As far as legibility is concerned, the landscape in photo 8 also appears reflected as a difficult place to explore or get around; it raises some doubts: "Raises superficial sensations, would not go to a place like this" and "It seems to me to be a place where I could guide/explore, but with some dangers associated with the unknown." Moreover, the legibility component of interpretation reinforces the notion that the landscape is "inhospitable, the presence of the house disturbs me, because it seems to be abandoned." Photo 13 shows low levels of readability. Respondents have difficulties in interpreting the space: "It seems to me like Mars - unreachable" and "It's a space without a reference. There is no form of guidance."

In photo 8 , the fact that the mystery evokes negative emotions stands out, such as "I see discomfort" and "It seems that at any moment there will be a fire." In photo 13, mystery is the strongest element as respondents have some doubts about what is happening in the photo although that curiosity is revealed as a negative feeling "Uncertainty, was it taken on earth?" and there is a promise of new information "Because I don't have references, I don't know where it is, it leads to something new."

\section{Positive Emotions}

The photos that evoke positive emotions in respondents are the photos 5, 6, 9, and 14. Photo 5 is perceived by the respondents as "exciting" and "pleasant" (see Fig. 2). This is due to the fact that it represents a highly coherent and logical landscape: "The photo has logic, I understand perfectly what the location is and what the attraction is." Also, this 
is a picture with as reasonable number of elements: a human figure, rocks, variety of shapes, chromatic contrast, sunset light, and centrality of the source of light as well as the dark sky. However, at the level of legibility, and in terms of safety in the context of space, this photo is the most controversial. On one hand the landscape is considered to be safe: "It seems to be without dangers (the grotto is a protective element)." However, the human presence is viewed as a threat: "Threat of human presence." In this photo, mystery is reflected by the curiosity that it generates in the respondents as they want to know more about the story behind the scene: "lack of knowledge about the place, makes me want to explore it further."

Photo 6 reflects a "tranquil" landscape, considered to be coherent as respondents can understand the picture at an immediate level: "The elements converge in the same direction" and "It's a logical image and it makes sense." It is full of easily identifiable elements, such as water, sun, nature, stones, lights, and river, which give the photo plenty of diversity. Respondents can easily explore and orient themselves in the scene they see: "It is a place I'd like to visit once, at least, to experience the serenity" and "It seems a soothing place, without danger. The open and illuminated landscape suggests peaceful exploration." Mystery is not the strongest dimension here, as its main elementwater - has a very similar effect as during the day: "The water and the margins set a path and orientation." The stones appear to be a controversial element as some respondents don't like the rocks: "Rocky floor."

Photo 9 was considered as "interesting" (see Fig. 2), which might be due to the structure and the organization of its elements in the space. Coherence is recognized by the respondents as they can identify the elements in the photo: "It's organized, and the image is coherent" and "The space, to me, seems organized and coherent and leaves me no doubts." Although the respondent identified a wide array of elements: trunks, blue sky, moon, vegetation shadows, and light; it's the magnificence of the trees that most impresses the respondents: "It doesn't look dangerous, the landscape dominated by the trunks and trees in the foreground." People like the trees (during the day) but in the darkness they lead to negative associations: "Obscure nature and little familiar" and "I associate them with dangers that I cannot identify or foresee." This particular photo encourages the exploration of new things, and generates curiosity and willingness to move further into the landscape: "Generates curiosity about the origin of the light that focuses on the tree" and "What lies beyond the curtain of trees in the illuminated background?"

Photo 14 presents the most positive emotion: "sensational" (see Fig. 2). Reasons for that rely on a generalized understanding of how the elements fit together: "Good organization of space to create an interesting contrast between the curve of the stars and the circle of the Menhirs" and "Space seems to me to be coherent and organized." However, this photo does not show a wide variety of elements, only basic ones: houses, sky, earth, and different types of lights. However, it pleased most of the respondents as they were able to read and interpret the space: "Wide and full landscape, seems free from dangers by finding themselves in the center of an illuminated circle" and "Ground plan clear sky, next to civilization." Moreover, this type of landscape creates the willingness to move further and explore: "No danger. It seems to me that there is a party in the background where there are lots of people who can help me in the orientation" and "It seems to me to be a place where one could orient/ explore with some dangers." All the respondents recognized some mystery in this environment, which gives them a positive feeling about the place: "Attracts and invites us to want to experience the place and this magnificent/magical sky," "I am curious to know what is in the surrounding space, pleasant place," and overall, "It's a magical site!"

\section{Conclusion}

Recently, the interpretation of photos has been recognized as an important research method and applied in a variety of settings (Bohnsack, 2008). Due to the abundance of photographic imagery (both professional and amateur) of many destinations, there are problems deciding which images should be used in marketing and promotional tourism materials (Page, Steele, \& Connell, 2006). This exploratory study evidences the need to deepen the study of this theme. The pictorial element is very relevant when a tourist is seeking information about 
a destination, especially when nonconventional photographs such as nightscape images are used. There is a risk that the tourist perception of the destination is different from the one that the tourism developers intend to promote (e.g., DMOs). The visual nightscape is dominated by shining points like stars on a generally darker background, very different from daytime pictures. When nightscape photography is used as a tool for scientific dissemination, it has a certain meaning, which is more relevant than the aesthetics and the perception of the landscape itself (Burriss \& Burriss, 2008). In the case of tourism promotion, it is very important to understand which elements in the picture could contribute to a positive perception and therefore lead to motivation to explore the destination. This study involved the analysis of nightscape pictures, which were selected using models applied to the study of daytime landscape preferences as basis. This is due to the scarcity of research on nightscape preferences and to verify if the criteria are similar.

The photos where the respondents expressed negative emotions $(3,4,8$, and 13$)$ present common features, namely obstructive elements such as trees, rocks, houses, and roads. Studies undertake by Fisher and Nasar (1992) and Nasar, Fisher, and Grannis (1993) also found that the physical conditions of a landscape (presence of trees, shrubs, and obstructed vistas) affect preferences after dark.

The pictures without a dominant emotion $(1,2$, $7,10,11$, and 12) also show common characteristics such as bridges, pathways, houses, trees, and diverse points that could obstruct the view. Nasar et al. (1993) suggested that, "reductions in places of concealment, increases in prospect, and reductions in obstructions to escapability may make an area less fearful" (p. 176). Our research findings are in line with previous studies (Fisher \& Nasar, 1992; Kim \& Abu Bakar, 2013; Nasar \& Fisher, 1993; Nasar et al., 1993) concluded generally people prefer open spaces free from visual obstructions that might cause fear and insecurity, and with points of light (e.g., celestial elements). One theory that could explain these preferences (spots of light and open spaces) is Appleton's (1975) prospect and refuge theory, which argues that humans prefer physical conditions that afford them prospect (an unobstructed view) and refuge. This could explain why the photos 5, 6, 9, and 14 evoked positive emotions among the respondents. These images have open spaces in common $(6,9$, and 14) and all of them show sources of light. Image 5 is the most contradictory; despite the presence of a grotto which could be an obstructive element, it has an intense source of light that could transmit security. Authors such as Narisada and Schreuder (2013), Mison (2012), and Falchi, Cinzano, Elvidge, Keith, and Haim (2011) claimed that people associate sources of light with security. In this photo, the human element is also controversial since it can have positive (security) or negative (threat) connotations.

In this study, we conclude that elements that are key during the day are not the same at night, such as complexity and points of reference. To the contrary, the preferred nightscape is based on simple open spaces, where the human eye could prospect security.

Further research is necessary in order to consolidate these findings and to determine if there are differences between amateur astronomers and tourists in general who have undertaken astrotouristic activities even sporadically. Also, future studies need to gather information about respondents with different nationalities and different cultural backgrounds. The main limitation of this study was the small sample, and the use of similar types of landscapes.

\section{Acknowledgment}

The pictures used in this study were supplied by the astrophotographer Miguel Claro to whom the researchers would like to express their gratitude. The authors gratefully acknowledge financial support from the Fundação da Ciência e Tecnologia (FCT).

\section{References}

Albers, P., \& James, W. (1988). Travel photography: A methodological approach. Annals of Tourism Research, 15(1), 134-158.

Appleton, J. (1975). The experience of landscape. London, UK: Wiley

Bakker, I., Vordt, T., \& Vink, P. (2014). Pleasure, arousal, dominance: Mehrabian and Russell revisited. Current Psychology, 33(3), 405-421.

Balling, J., \& Falk, J. (1982). Development of visual preference for natural environments. Environment and Behaviour, 14(1), 5-38.

Baloglu, S., \& McCleary, K. W. (1999). A model of destination image formation. Annals of Tourism Research, 26, 268-897. 
Banks, M. (2001). Visual methods in social research. London, UK: Sage.

Bohnsack, R. (2008). The interpretation of pictures and the documentary method. Forum: Qualitative Social Research, 9(3), 1-24.

Burriss, L., \& Burriss, K. (2008). Gender differences related to co-orientation discrepancy in NASA Space photography. Visual Communication Quarterly, 15(4), 258-265.

Burton, R. (1999). Landscape evaluation. In M. Pacione (Ed.), Applied geography: Principles and practice (pp. 222-236). London, UK: Routledge.

Collier, J., Jr. (1967). Visual anthropology: Photography as a research method. New York, NY: Holt, Rinehart, \& Winston.

Coshall, J. T. (2000). Measurement of tourists' images: The repertory grid approach. Journal of Travel Research, 39, 85-89.

Dann, G. (1996). Tourists' images of a destination-An alternative analysis. Journal of Travel and Tourism Marketing, 5, 41-55.

Downes, M., \& Lang, E. (2015). What you see is not always what you get, a qualitative, comparative, comparative analysis of ex ante visualizations with ex post photography of landscape and architectural projects. Landscape and Urban Planning, 142, 136-146.

Echtner, C., \& Ritchie, B. (1993). The measurement of destination image: An empirical assessment. Journal of Travel Research, 31(4), 3-13.

Falchi, F., Cinzano, P., Elvidge, C., Keith, D., \& Haim, A. (2011). Limits the impact on human health, environment and stellar visibility. Journal of Environmental Management, 92(10), 2714-2722.

Fayos-Solà, E., Marín, C., \& Jafari, J. (2014). Astrotourism: No requiem for meaningful travel. Pasos, 12(4), 663-671.

Feighey, W. (2003). Negative image? Developing the visual in tourism research. Current Issues in Tourism, 6(1), 76-85.

Fisher, B., \& Nasar, J. (1992). Fear of crime in relation to three exterior site features. Environment and Behavior, 24(1), 35-65.

Gallarza, G., Saura G., \& Garcia, H. (2002). Destination image: Towards a conceptual framework. Annals of Tourism Research, 29(1), 56-78.

Garrod, B. (2009). Understanding the relationship between tourism destination imagery and tourist photography. Journal of Travel Research, 47(3), 346-358.

Gobster, P., Nasauer, J., Daniel, T., \& Fry, G. (2007). The shared landscape: What does aesthetics to do with ecology? Landscape Ecology, 22(7), 959-972.

Harper, D. (1984). Meaning and work: A study in photoelicitation. International Journal of Visual Photography, 2, 20-43.

Harper, D. (1997). Visualizing structures: Reading surfaces of social life. Qualitative Sociology, 20, 57-74.

Harper, D. (2002). Talking about pictures: A case for photoelicitation. Visual Studies, 17(1), 13-26.

Heisley, D. D. (2001). Visual research: Current bias and future direction. Advances in Consumer Research, 28, 45-47.
Herzog, T. (1987). A cognitive analysis of preference for urban nature. Journal of Environmental Psychology, 9(1), 27-43.

Hunt, J. D. (1975). Image as a factor in tourism development. Journal of Travel Research, 13, 1-7.

Jacobsen, J. K. S. (2007). Use of landscape perception methods in tourism studies: A review of photo-based research approaches. Tourism Geographies: An International Journal of Tourism Space, Place and Environment, 9(3), 234-253.

Jenkins, O. H. (1999). Understanding and measuring tourist destination images. International Journal of Tourism Research, 1, 1-15.

Kaplan, R., \& Kaplan, S. (1989). The experience of nature: A psychological perspective. Cambridge, UK: Cambridge University Press.

Kim, H., \& Stepchenkova, S. (2015). Effect of tourism photographs on attitudes towards destination: Manifest and latent content. Tourism Management, 49, 29-41.

Kim, M., \& Abu Bakar, S. (2013). Anightscape preference study using eye movement analysis. Alam Cipta, 6(2), 85-99.

Krippendorf, K. (1980). Content analysis: An introduction to its methodology. Thousand Oaks, CA: Sage.

Lester, J., \& Scarles, C. (2013). Mediating the tourist experience, from brochures to virtual encounters. London, UK: Routledge.

Litton, R. (1972). Aesthetic dimensions of the landscape. In J. V. Krutilla (Ed.), Natural environments: Studies in theoretical and applied analysis (pp. 262-291). Baltimore, MD: John Hopkins University Press.

Mackay, K. (2005). Is a picture worth a thousand words? Snapshots from tourism destination image research. In J. Arramberri \& R. Butler (Eds.), Tourism development: Issues for a vulnerable industry (pp. 44-66). Clevedon, UK: Channel View Publications.

Miles, M., \& Huberman A. (1994). Qualitative data analysis: An expanded source book. Thousand Oaks, CA: Sage Publications.

Milhaud, D. (2001). Qualitative methodologies for geographers: Issues and debates. New York. NY: Oxford University Press.

Mison, B. (2012). Light pollution, responses and remedies (2nd ed.). Heidelberg, Germany: Springer.

Narisada, K., \& Schroeder, D. (2013). Light pollution handbook (Vol. 1). Heidelberg, Germany: Springer.

Nasar, J., \& Fisher, B. (1993). "Hot spots" of fear and crime: A multimethod investigation. Journal of Environmental Psychology, 13, 187-206.

Nasar, J., Fisher, B., \& Grannis, M. (1993). Proximate physical cues to fear of crime. Landscape and Urban Planning, 26(1), 161-178.

Pachmayer, A., \& Andereck, K. (2017). Photo-elicitation in tourism research: Investigating the travel experiences of study abroad participants. In 2017 TTRA International Conference. Tourism Travel and Research Association: Advancing Tourism Research Globally. 3. Retrieved from https://scholarworks.umass.edu/cgi/viewcontent.cgi? article $=2057 \&$ context $=$ tra 
Page, S., Steele, W., \& Connell, J. (2006). Analysing the promotion of adventure tourism: A case study of Scotland. Journal of Sport and Tourism, 11(1), 51-76.

Pan, S., Lee, J., \& Tsai, H. (2014). Travel photos: Motivations, image dimensions, and affective qualities of places. Tourism Management, 40, 59-69.

Patton, M. Q. (2002). Qualitative research and evaluation methods. Thousand Oaks, CA: Sage.

Pearce, P. (1988). The Ulysses factor. New York, NY: Springer-Verlag.

Pike, S. (2007). Repertory grid analysis in group settings to elicit salient destination image attributes. Current Issues in Tourism, 10(4), 378-392.

Pritchard, A., \& Morgan, N. (2003). Mythic geographies of representation and identity: Contemporary postcards of Wales. Journal of Tourism and Cultural Change, 1(2), $111-130$

Reilly, M. D. (1990). Free elicitation of descriptive adjectives for tourism image assessment. Journal of Travel Research, 28(4), 21-26.

Richard, V., \& Lahman, M. (2015). Photo-elicitation: Reflexivity on method, analysis, and graphic portraits. International Journal of Research \& Method in Education, 38(1), 3-22.

Rodrigues, A. (2018). Insights and perspectives about textual with visual data analysis: The use of photos as an example. In A. P. Costa, L. P. Reis, F. N. de Souza, \& A. Moreira (Eds.), Computer supported qualitative research, ISQR2017. Advances in intelligent systems and computing (pp. 291-305). Cham, Switzerland: Springer.

Rodrigues, A., Correia, A., \& Kozak, M. (2012). Exploring the life-cycle model applied to 'umbrella constructs': Destination image as an example, Tourism Recreation Research, 37(2), 133-143.

Rodrigues, A., Correia, A., Kozak, M., \& Tuohino, A. (2015). Lake-destination image attributes: Content analysis of text and pictures. In A. Correia, J. Gnoth, M. Kozak, \& A. Fyall, A. (Eds.), Marketing places and spaces (Advances in Culture, Tourism and Hospitality Research, Vol. 10, pp. 293314). Bingley, UK: Emerald Group Publishing Limited.

Russel, J., \& Lanius, U. (1984). Adaptation level and the affective appraisal of environments. Journal of Environment Psychology, 4, 119-135.

Saldaña, J. (2009). The coding manual for qualitative researchers. London, UK: Sage.

Tveit, M., Sang, A., \& Hagerhall, C. (2012). Scenic beauty: Visual landscape assessment and human landscape perception. In L. Steg, A. Van der Berg \& J. De Groot (Eds.), Environmental psychology: An introduction (pp. 37-47). New York, NY: BPS Blackwell.

Wang, Y., \& Sparks, B. (2016). An eye-tracking study of tourism photo stimuli: Image characteristics and ethnicity. Journal of Travel Research, 55(5), 588-602.

Weaver, D. (2011). Celestial ecotourism: New horizons in nature-based tourism. Journal of Ecotourism, 10(1), $38-45$. 
